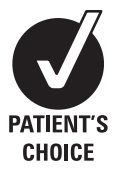

- Additional materials are published online only. To view these files please visit the journal online (http://jnnp.bmj. com/content/83/1.toc)

${ }^{1}$ Department of Clinical Neurosciences, School of Molecular and Clinical Medicine, University of Edinburgh, Western General Hospital, Edinburgh, UK

${ }^{2}$ Psychological Medicine Research, School of Molecular and Clinical Medicine, University of Edinburgh, Royal Edinburgh Hospital, Edinburgh, UK

Correspondence to Dr J Stone, Department of Clinical Neurosciences, Western General Hospital, Edinburgh EH4 2XU,UK; jon.stone@ed.ac.uk

Received 24 March 2011 Revised 25 May 2011 Accepted 7 July 2011 Published Online First 11 August 2011

\title{
Functional weakness: clues to mechanism from the nature of onset
}

\author{
Jon Stone, ${ }^{1}$ Charles Warlow, ${ }^{1}$ Michael Sharpe ${ }^{2}$
}

\section{ABSTRACT}

Background Functional weakness describes weakness which is inconsistent and incongruent with disease. It is also referred to as motor conversion disorder (DSM-IV), dissociative motor disorder (ICD-10) and 'psychogenic' paralysis. Studies of aetiology have focused on risk factors such as childhood adversity and life events; information on the nature and circumstance of symptom onset may shed light on the mechanism of symptom formation.

Aim To describe the mode of onset, associated symptoms and circumstances at the onset of functional weakness.

Methods Retrospective interviews administered to 107 adults with functional weakness of $<2$ years' duration.

Results The sample was $79 \%$ female, mean age 39 years and median duration of weakness 9 months. Three distinct modes of onset were discerned. These were: sudden $(n=49,46 \%)$, present on waking (or from general anaesthesia) $(n=16,13 \%)$ or gradual $(n=42$, $39 \%)$. In 'sudden onset' cases, panic $(n=29,59 \%)$, dissociative symptoms $(n=19,39 \%)$ and injury to the relevant limb $(n=10,20 \%)$ were commonly associated with onset. Other associated symptoms were non-epileptic attacks, migraine, fatigue and sleep paralysis. In six patients the weakness was noticed first by a health professional. In $16 \%$ of all patients, no potentially relevant factors could be discerned.

Conclusions The onset of functional weakness is commonly sudden. Examining symptoms and circumstances associated closely with the onset suggests hypotheses for the mechanism of onset of weakness in vulnerable individuals.

\section{INTRODUCTION}

Functional weakness describes the symptom of weakness, usually of a limb, that is both internally inconsistent with neurological findings and incongruent with a recognisable neurological disease. Conversion disorder, dissociative motor disorder and psychogenic paralysis are different names for the same phenomenon.

Many non-specific risk factors for the development of functional weakness, such as childhood adversity, psychiatric disorder and adverse life events $^{12}$ are known. However, we know much less about the nature of onset of functional weakness. Such observations may provide important clues to the mechanism of symptom formation.

As part of a study of functional weakness, ${ }^{2} 107$ patients underwent detailed interviews which included an enquiry about the onset of the weakness. In this paper, we aim to describe and catego- rise patient reports of the mode of onset and associated symptoms and circumstances.

\section{METHODS}

\section{Recruitment and selection}

Patients with functional weakness were recruited over 2.5 years by referral from all nine consultant neurologists providing the National Health Service neurology service to South East Scotland, a population of approximately 1 million. Approval was obtained from the Lothian Research Ethics Committee and all patients provided written consent to participate.

Inclusion criteria were: (1) the patient complained of weakness and was referred to a neurologist; (2) symptoms were judged by a consultant neurologist to be unexplained by organic disease; (3) symptom onset was within the previous 2 years; (4) weakness was judged not to be solely a result of pain or fatigue; and (5) weakness was not in part due to a known neurological disease. In order to recruit representative patients, no constraints were placed on the extent of the investigation that the patient had to undergo to be eligible for the study.

Following written consent, face to face interviews were carried out by JS in the subjects' homes $(72 \%)$, in the hospital ward $(17 \%)$ or in the outpatient clinic (11\%). A semi-structured interview elicited a retrospective account of the speed of onset and associated symptoms and circumstances in the $24 \mathrm{~h}$ prior to onset.

Operational criteria were used to describe the presence of a panic attack (DSM-IV criteria for panic disorder), migraine (International Headache Society classification of migraine or migraine with aura) and dissociative symptoms (the presence of depersonalisation or derealisation). Non-epileptic attacks, when present, were diagnosed by a consultant neurologist on the basis of the witness history.

The reports are described and tabulated by mode of onset. This was an observational study and there were no a priori hypotheses.

\section{RESULTS \\ Recruitment and basic characteristics}

A total of 192 patients were referred by consultant neurologists during the study period. Sixty-seven patients were excluded (48 had a duration of more than 2 years; 16 had the wrong symptoms; 12 had comorbid organic disease; and one patient was deaf/mute). Of 115 eligible patients, five were uncontactable, two refused to take part and one did 
not complete the interview, leaving 107 cases. Mean age of the interviewed sample was 39 years; 85 (79\%) were women and mean symptom duration was 9 months (IOR 4-16 months). The pattern of weakness was: hemiparesis ( $n=67,63 \%)$; monoparesis $(n=17,16 \%)$; triparesis $(n=3,3 \%)$; paraparesis $(n=11,10 \%)$; and tetraparesis $(n=9,8 \%)$. Eight of the patients no longer had weakness at the time of the interview. Other characteristics of these patients have been described in detail elsewhere. $^{2}$

\section{Mode of onset}

Forty-nine patients (46\%) reported sudden onset of weakness while awake, 16 (15\%) reported first experiencing symptoms on waking (or after coming round from general anaesthesia) and the remaining 42 patients (39\%) reported a gradual onset (more than $6 \mathrm{~h}$ to maximal onset).

\section{Symptoms and circumstances at onset}

Table 1 shows the frequency of associated symptoms and events at onset overall and according to whether the onset was sudden, on waking or gradual. No relevant factors were reported by $19 \%$. More detailed discussion and examples of each of these factors at onset is provided in the supplementary material (available online only).

\section{Sudden onset $(n=49)$}

Fifty-nine per cent of the patients with sudden onset reported a panic attack $(n=29)$ and $39 \%$ reported dissociative symptoms $(n=19,39 \%)$. Physical injury to the relevant limb $(n=10,20 \%)$ was the next most frequent category (and four more patients had pain at onset (8\%)). Other reported associated symptoms were migraine $(n=5,10 \%)$ and non-epileptic attacks $(n=6,12 \%)$. Twenty five of these sudden onset patients were recorded as having multiple factors and overlap of these is shown in figure 1. The majority (69\%) reported at least one of the following: panic, dissociative symptoms (which commonly occur with panic) or non-epileptic attacks (which are known to overlap considerably with panic attacks $\left.{ }^{3}\right)$.

\section{Waking onset $(n=16)$}

In the waking onset group, sleep paralysis (associated with insomnia) $(n=2)$ and general anaesthesia $(n=2)$ were reported.

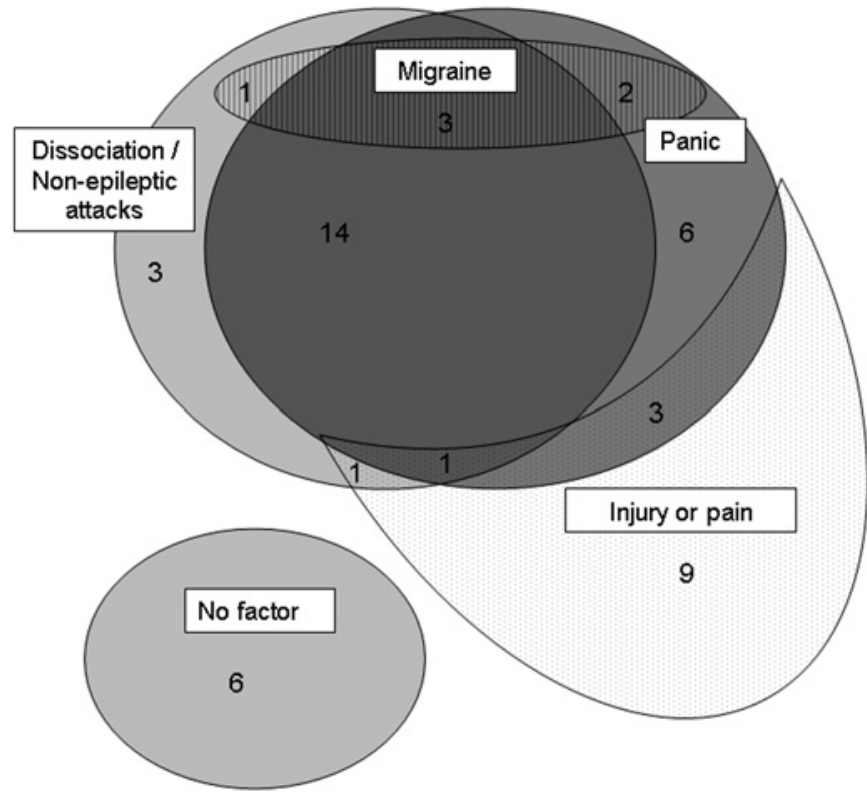

Figure 1 Overlap of associated symptoms associated with onset of functional weakness in patients with sudden onset of symptoms $(n=49)$. Numbers represent absolute numbers of patients (diagram only roughly to scale).

Patients with waking onset also described panic $(n=4)$, dissociative symptoms $(n=3)$ or pain $(n=6)$ occurring from the moment of waking.

Gradual onset $(n=42)$

In patients with gradual onset, weakness fatigue $(n=11,26 \%)$ and pain ( $n=12,29 \%)$ were the commonest associated factors. Patients often gave a description of generalised fatigue that evolved to a feeling that one half of their body was 'more tired' and weak than the other half. Interestingly, in six patients, the first time they became aware of the weakness was when it was noticed by a health professional.

\section{DISCUSSION}

We found that reports of mode of onset of functional weakness could be categorised as sudden, from sleep or gradual. We are not aware on any other reports on mode of onset in relation to

Table 1 Symptoms and circumstances reported at onset of functional weakness in 107 cases by mode of onset

\begin{tabular}{|c|c|c|c|c|c|c|c|c|}
\hline \multirow[b]{2}{*}{ Factor at onset } & \multicolumn{2}{|c|}{ All cases $(n=107)$} & \multicolumn{2}{|c|}{$\begin{array}{l}\text { Sudden onset } \\
(n=49)\end{array}$} & \multicolumn{2}{|c|}{$\begin{array}{l}\text { Waking onset } \\
(n=16)\end{array}$} & \multicolumn{2}{|c|}{$\begin{array}{l}\text { Gradual onset } \\
(n=42)\end{array}$} \\
\hline & $\bar{n}$ & $\%$ & $\bar{n}$ & $\%$ & $\bar{n}$ & $\%$ & $\bar{n}$ & $\%$ \\
\hline Panic attack* & 36 & 34 & 29 & 59 & 4 & 25 & 3 & 7 \\
\hline Dissociative symptoms & 27 & 25 & 19 & 39 & 3 & 19 & 5 & 12 \\
\hline Pain & 22 & 21 & 4 & 8 & 6 & 38 & 12 & 29 \\
\hline Fatigue & 14 & 13 & 0 & 0 & 3 & 19 & 11 & 26 \\
\hline Migraine† & 8 & 7 & 5 & 10 & 1 & 6 & 2 & 5 \\
\hline Non-epileptic attack & 8 & 7 & 6 & 12 & 0 & 0 & 2 & 5 \\
\hline Sleep paralysis & 2 & 2 & 0 & 0 & 2 & 13 & 0 & 0 \\
\hline Physical injury to relevant limb & 11 & 10 & 10 & 20 & 0 & 0 & 1 & 2 \\
\hline Prolonged bed rest & 5 & 5 & 1 & 2 & 1 & 6 & 3 & 7 \\
\hline General anaesthesia & 2 & 2 & 0 & 0 & 2 & 13 & 0 & 0 \\
\hline First noticed by health professional & 6 & 6 & 0 & 0 & 0 & 0 & 6 & 14 \\
\hline No identifiable factors & 20 & 19 & 6 & 12 & 2 & 13 & 12 & 29 \\
\hline
\end{tabular}

*Fulfilling DSM-IV criteria for a panic attack.

†Fulfilling International Headache Society criteria for migraine or migraine with aura. 
functional weakness although sudden onset has been previously recognised in studies of 'pseudostroke'. 45

Our study has some limitations. These are retrospective accounts by patients and were limited to what they reported. Recall bias may have led patients to over report some eventsfor example, physical injury. Important psychological triggers may have been omitted from their accounts and we have not attempted to describe the onset of symptoms in the context of recent life events. Furthermore, we cannot determine whether the nature of the relationship between the factors described is causal or mere association. Finally, the sample was of patients referred to neurology and may not be representative of all patients.

We identified certain symptoms and circumstances associated with the onset of functional weakness, such as panic, dissociation, pain and physical injury. These offer potential clues to the mechanism by which the specific symptom of functional weakness may develop. Some of these mechanisms were described in the clinical literature of the 19th and early 20th centuries. Later hypotheses focused largely on more distant antecedents and less tangible mechanisms, such as symbolism.

\section{Panic and dissociation}

Janet described many patients with panic and dissociative symptoms at the onset of their 'hysterical' symptoms. ${ }^{6}$ Hyperventilation, common in panic, induces unilateral sensory symptoms in a small proportion of healthy volunteers-a plausible initiating mechanism for more prolonged unilateral functional symptoms. ${ }^{7}$ A study of dissociative seizures (nonepileptic attacks) found a high frequency of (often initially undisclosed) panic occurring as an integral part of the attack. ${ }^{3}$ The presence of dissociative symptoms (and dissociative (nonepileptic) seizures) at onset supports the notion, embodied in the ICD-10 diagnosis 'dissociative motor disorder', that functional weakness may be a form of 'hemi-depersonalisation' or compartmentalisation. ${ }^{8}$ 'Hysterical paralysis' emerging from 'hystero-epilepsy' was described in older literature, including that of Todd. ${ }^{9}$ Dissociation and panic are also plausible mechanisms to explain symptoms of paralysis arising out of general anaesthesia (also a documented trigger for dissociative (non-epileptic) seizures ${ }^{10}$ ) and sleep paralysis.

\section{Physical trauma and pain}

The diagnosis of 'traumatic hysteria' was devised in the 19th century to describe the occurrence, often in men, of symptoms identical to hysteria seen in women but occurring after physical injury. There was fierce debate, especially before World War I, whether they were the same or different conditions, and whether the traumatic variety was predominantly organic. ${ }^{11}$ These debates mirrored those seen in 'shell shock' and more recently complex regional pain or reflex sympathetic dystrophy. A systematic review of studies of motor or sensory conversion symptoms noted a surprisingly high frequency of physical injury at onset (37\% of 869 patients), documented largely without comment. ${ }^{12}$ A study of non-epileptic attacks also found a high rate of reported head injury (32\% of 102 patients). ${ }^{13}$ There are multiple potential relationships between physical injury and functional weakness, including immobility, attention paid to a body part, recall bias and iatrogenesis as part of a legal process.

\section{Migraine}

Migraine has been described as a trigger for 'give way' (ie, functional) weakness under the name 'migraine with unilateral motor symptoms' ${ }^{14}$ Authors including Babinski have suggested a relationship between migraine and psychogenic symptoms. ${ }^{15} 16$ A migrainous motor or sensory symptom, experienced in the context of anxiety, could, through increased attention, persist beyond the immediate migrainous aura.

\section{Fatigue}

The prodrome of fatigue in patients with gradual onset of weakness also lends itself to a hypothesis. Patients with gradually evolving asymmetrical weakness could be experiencing a mixture of depersonalisation symptoms, frequently associated with fatigue states, combined with attention and anxiety in relation to naturally occurring asymmetries in volition and movement.

\section{CONCLUSION}

We conclude that it is useful to study not only risk factors which predispose patients to develop functional weakness but also immediate factors at onset, such as a panic attack or physical injury. The events described here are potential clues to the mechanism of the development of functional weakness and merit further study. There could also be advantages for treatment in being able to explain functional weakness in terms of psychophysiological mechanisms, even if the more remote aetiology of patients' symptoms remains hard to disentangle.

\section{Competing interests None.}

Ethics approval Approval was obtained from the Lothian Research Ethics Committee.

Contributors JS, CW and MS designed the study and wrote the manuscript. JS collected and analysed data.

Provenance and peer review Not commissioned; externally peer reviewed.

\section{REFERENCES}

1. Binzer M, Andersen PM, Kullgren G. Clinical characteristics of patients with motor disability due to conversion disorder: a prospective control group study. J Neurol Neurosurg Psychiatry 1997;63:83-8.

2. Stone J, Warlow C, Sharpe M. The symptom of functional weakness: a controlled study of 107 patients. Brain 2010;133:1537-51.

3. Goldstein LH, Mellers JD. Ictal symptoms of anxiety, avoidance behaviour, and dissociation in patients with dissociative seizures. J Neurol Neurosurg Psychiatry 2006;77:616-21

4. Chernyshev OY, Martin-Schild S, Albright KC, et al. Safety of tPA in stroke mimics and neuroimaging-negative cerebral ischemia. Neurology 2010;74:1340-5.

5. Nazir FS, Lees KR, Bone I. Clinical features associated with medically unexplained stroke-like symptoms presenting to an acute stroke unit. Eur J Neurol 2005; 12:81-5

6. Janet $\mathbf{P}$. The major symptoms of hysteria. London: Macmillan, 1907

7. Fleminger JJ, McClure GM, Dalton R. Lateral response to suggestion in relation to handedness and the side of psychogenic symptoms. Br J Psychiatry 1980; 136:562-6.

8. Holmes EA, Brown RJ, Mansell W, et al. Are there two qualitatively distinct forms of dissociation? A review and some clinical implications. Clin Psychol Rev 2005; $25: 1-23$

9. Todd RB. Clinical lectures on paralyses. Diseases of the brain, and other affections of the nervous system. London: J.Churchill, 1854.

10. Reuber M, Enright SM, Goulding PJ. Postoperative pseudostatus: not everything that shakes is epilepsy. Anaesthesia 2000;55:74-8.

11. Trimble MR. Post-traumatic neurosis: from railway spine to the whiplash Chichester: John Wiley \& Sons, 1981.

12. Stone J, Carson A, Aditya $\mathrm{H}$, et al. The role of physical injury in motor and sensory conversion symptoms: a systematic and narrative review. J Psychosom Res 2009;66:383-90.

13. Westbrook LE, Devinsky 0, Geocadin R. Nonepileptic seizures after head injury Epilepsia 1998;39:978-82.

14. Young WB, Gangal KS, Aponte RJ, et al. Migraine with unilateral motor symptoms: a case-control study. J Neurol Neurosurg Psychiatry 2007;78:600-4.

15. Sanchez-Villasenor F, Devinsky 0, Hainline B, et al. Psychogenic basilar migraine: report of four cases. Neurology 1995;45:1291-4.

16. Babinski J. De la migraine ophthalmique hystérique. Arch Neurol 1890;20:305-35. 